\title{
Study of maternal and perinatal outcome in referred obstetric cases.
}

\author{
Mahendra G ${ }^{1}$, Kavya B. S. ${ }^{2}$, Pukale R. S. ${ }^{3}$ \\ ${ }^{1}$ Dr. Mahendra G., Associate Professor, ${ }^{2}$ Dr. Kavya B.S., Junior Resident, ${ }^{3}$ Prof Dr. Ravindra S Pukale, Professor and \\ Head, all authors are affiliated with Department of Obstetrics and Gynaecology, Adichunchnagiri Institute of Medical \\ Sciences, Karnataka, India.
}

Corresponding Author: Dr. Kavya B.S, Junior resident, Department of Obstetrics and Gynaecology, Adichunchnagiri Institute of Medical Sciences, Karnataka, India. Email: k8kavya@gmail.com

\begin{abstract}
Objective- to review the referred obstetric cases for reason of referral and to study the maternal and perinatal outcome. Design- Prospective study. Study period- May 2017 to June 2018. Study population-All obstetric cases referred to the department of obstetrics and gynaecology of Adichuchanagiri Hospital, B G Nagara during the study period. Results- In the present study, maximum number of patients (62.96\%) were in the 20-30 years of age group. Majority of the referral cases were primigravida $65(48.1 \%)$. Out of 135 referred cases, $106(78.51 \%)$ delivered $18(13.3 \%)$ were treated conservatively. In 11 patients $(8.1 \%)$ either abortion occurred or medical termination of pregnancy was done or there was ectopic pregnancy or tears. Out of the 106 cases who delivered at our institute majority of the babies were delivered 65(61.3\%) delivered normally, while 41 (38.67\%) underwent caesarean section. There were 25 NICU admissions and 81 were healthy babies. Reasons for admission were varied. In the present study, premature rupture of membranes was the most common cause of referral. This is followed by pre-eclampsia and related conditions, and preterm labour being the next common cause.
\end{abstract}

Key words: referred obstetric cases, Perinatal outcome, neonatal outcome.

\section{Introduction}

Pregnancy and childbirth are physiological processes. However they are not free of risks. Despite progress in medical field and improvement in available health care facilities, maternal mortality is still high in our country [1]. The objective of antenatal care is to detect high risk cases as early as possible from large group of antenatal patients and arrange them for skilled care. Therefore antenatal care, the primary aim of which is to achieve at the end of pregnancy a healthy mother and a healthy child, should be provided to every woman [2].

Due to lack of awareness and absence of regular antenatal care, the critically ill patients are referred late and sometimes in moribund conditions with multiple organ damage. Timeliness and appropriateness of referral is an important factor in the ultimate outcome of the patients [3]. Referral services for identification and referral of high risk pregnancies are an integral part of maternal and child health services. For a large majority of developing countries this aspect of health system

Manuscript received: $10^{\text {th }}$ June 2019

Reviewed: $20^{\text {th }}$ June 2019

Author Corrected: $26^{\text {th }}$ June 2019

Accepted for Publication: $30^{\text {th }}$ June 2019 remains weak [4]. Although most obstetric complications (defined as acute conditions such as postpartum haemorrhage, sepsis, eclampsia, and obstructed labor that can cause maternal death cannot be predicted, the majority can be treated with timely provision of a package of evidence-based interventions known as emergency obstetric care (EmOC) [5-7].

The availability of EmOC is considered to be an indicator of how well a health system is prepared to manage conditions leading to acute maternal morbidity and mortality $[8,9]$. Em OC refers to elements of obstetric care needed for management of complications during pregnancy, delivery and postpartum period, skilled personnel, equipment and support services. EmOC services are of paramount importance in reducing maternal mortality and morbidity [10].

It is still recommended to electively refer pregnant woman with previous caesarean section, breech presentation, transverse lie, multiple gestation, hypertension and severe anaemia for delivery before any complication arise to a health care centre where all 


\section{Original Research Article}

the facilities to deal with the complications are available [10]. With this background present study was undertaken to evaluate the maternal and perinatal outcome in referred cases.

\section{Materials and Methods}

Study design- Prospective study

Study period- May 2017 to June 2018

Study population-All obstetric cases referred to the department of obstetrics and gynaecology of Adichunchanagiri hospital and research centre, BG Nagara during the study period.

\section{Data collection}

1. The study data was collected from case sheets of patients referred and managed at our hospital.

2. Detailed clinical history, place of referral, cause of referral was studied.

3. Complete physical and obstetric examination was done and relevant investigations were done.

4. Management of the patient, clinical course, mode of delivery (vaginal or operative or conservative) and maternal outcome was documented.

5. To know perinatal outcome, APGAR score was noted, if needed NICU admission cause for it was noted.

DESCRIPTIVE STATISTICS like percentages were used for analysis.

\section{Results}

Secondary data analysis of referral slips to our hospital, Adichunchanagiri hospital, was done. After thorough analysis of data following observations are put forward. A total of 135 cases were referred to the higher centre due to various reasons. Copy of all referral slips had been preserved. These referral slips have been studied retrospectively.

Maximum number of cases in present study were in the age group of 20-30 years comprising $62.96 \%$ of total cases.

Table 1: Age Distribution

\begin{tabular}{|c|c|}
\hline$<20$ years & 36 \\
\hline $20-30$ years & 85 \\
\hline$>30$ years & 14 \\
\hline
\end{tabular}

Majority of the referral cases were primigravida 65 (48.1\%).

Table 2:Parity-Wise Distribution

\begin{tabular}{|c|c|}
\hline Primigravida & 65 \\
\hline Multigravida & 63 \\
\hline Grand multigravida & 7 \\
\hline
\end{tabular}

Out of 135 referred cases, $106(78.51 \%)$ delivered 18 (13.3\%) were treated conservatively. In 11 patients $(8.1 \%)$ either abortion occurred or medical termination of pregnancy was done or there was ectopic pregnancy or tears which were managed according to set protocol depending upon the gestational age at diagnosis.

Table 3: Outcome of the Antenatal Cases

\begin{tabular}{|c|c|c|}
\hline Outcome of ANC & No. of cases & Percentage \\
\hline Delivered & 106 & 78.5 \\
\hline Abortion /ectopic & 11 & 8.1 \\
\hline Conservative & 18 & 13.3 \\
\hline Total & $\mathbf{1 3 5}$ & $\mathbf{1 0 0}$ \\
\hline
\end{tabular}

Out of the 106 cases who delivered at our institute majority of the babies were delivered $65(61.3 \%)$ delivered normally, while 41 (38.67\%) underwent caesarean section. 
Table 4: Mode of Delivery.

\begin{tabular}{|c|c|}
\hline \multicolumn{2}{|c|}{} \\
\hline Normal Delivery & 65 \\
\hline LSCS & 41 \\
\hline
\end{tabular}

Out of 106 deliveries, there were 25 NICU admissions and 81 were healthy babies. Reasons for admission were varied.

Table 5: Reasons for NICU Admission.

\begin{tabular}{|l|c|c|}
\hline \multicolumn{1}{|c|}{ Reason for admission } & No. of cases & Percentage \\
\hline Preterm care & 10 & 40 \\
\hline Meconium aspiration syndrome & 6 & 12 \\
\hline Jaundice & 3 & 4 \\
\hline Sepsis & 2 & 8 \\
\hline Transient tachypnoea of newborn & 1 & 4 \\
\hline Low birth weight & 1 & 4 \\
\hline Asphyxia+ death & 1 & 4 \\
\hline Hypoglycaemia & $\mathbf{2 5}$ & $\mathbf{1 0 0}$ \\
\hline
\end{tabular}

In the present study, premature rupture of membranes was the most common cause of referral. This is followed by preeclampsia and related conditions, and preterm labour being the next common cause.

Table 6: Causes of referral.

\begin{tabular}{|l|l|}
\hline Preterm Labour & 11 \\
\hline PROM & 20 \\
\hline Pre-eclampsia and related condition & 19 \\
\hline Cardiac disease & 1 \\
\hline Crossed dates & 9 \\
\hline Prev LSCS & 6 \\
\hline Antepartum hemorrhage & 8 \\
\hline Postpartum hemorrhage & 6 \\
\hline MSAF & 15 \\
\hline Malpresentation & 2 \\
\hline Non availability of blood & 6 \\
\hline Non availability of doctor & 4 \\
\hline No details & 7 \\
\hline Ectopic & 1 \\
\hline Short stature & 2 \\
\hline Anaemia & 9 \\
\hline Fetal distress & 9 \\
\hline
\end{tabular}

Out of 135 referrals, most common referral was during intra-partum period. Intranatal referral was done in 89 (65.9\%) cases. 
Original Research Article

Table 7: Most common period during which patients were referred.

\begin{tabular}{|c|c|c|}
\hline Period of pregnancy & No. of cases & Percentage \\
\hline Intrapartum & 89 & 65.9 \\
\hline Antenatal & 34 & 25.1 \\
\hline Postpartum & 12 & 8.8 \\
\hline Total & $\mathbf{1 3 5}$ & $\mathbf{1 0 0}$ \\
\hline
\end{tabular}

\section{Discussion}

Labour is a physiological process, but it carries an inherent risk of complications. Obstetrical care in the western world is at its peak. But in developing countries it is still at docks due to illiteracy, male dominant society and untrained birth attendants. Majority of the population living in the rural areas do not have accessibility to the maternity centres and may develop life threatening complications during labour [11].

The death of a woman in childbirth is a tragedy, an unnecessary and wasteful event that carries with it the huge burden of grief and pain. Pregnancy is not a disease and pregnancy related morbidity and mortality are almost preventable. Identification of atrisk patients and obstetrics emergencies and timely referral is of immense importance [10].

Morsheda Banu et al on assessing the overall age distribution found that the majority $(74 \%)$ of the respondents were between 20-35 years [12]. In the study conducted by Prakriti Goswami et al, the maximum number of patients were in the age group of 20-30 years (78\%) [10]. Similar kind of results was observed in the present study.

Gupta PR et al found $52.17 \%$ patients were primigravida [13], Prakriti Goswami et al found 47\% patients were primigravida [10], Morsheda Banu et al had found that $50 \%$ of women were primigravida[12], which is comparable to the $48 \%$ primigravida cases found in the present study.

$65.9 \%, 25.1 \%, 8.8 \%$ of the cases were referred to our hospital in their intapartum, antepartum and postpartum period respectively. Similar results are found by Prakriti Goswami et al where $56 \%, 30 \%$ and $14 \%$ of cases were referred in intrapartum, antepartum, postpartum period respectively [10] and also by Devinneni K et alin their "Study of spectrum of referral pattern at a tertiary teaching hospital toward better obstetric care"[14]. Out of the 106 cases who delivered at our institute majority of the babies were delivered $61.3 \%$ delivered normally, while $38.67 \%$ underwent caesarean section. Similar results were obtained by Gupta PR et al where $69.48 \%$ of the patients underwent vaginal delivery and $22.75 \%$ of the patients had LSCS [13]. The caesarean section rates in the present study was found to be similar to the study conducted by Goswami et al (28\%)[10]. In the present study, it can be concluded that the rate of caesarean section is substantially high in referred cases.

Patel HC et al in their study found that causes of referral were pre-eclampsia (16\%) and meconiumstained liquor (5\%) [15]. Sabale et al in their study found that preeclampsia and related conditions were a major indication for referral (25.79\%) [2]. Rathi Charu et al noted that a majority of the cases were referred for preeclampsia and related conditions (26\%), preterm labour (26\%) and medical disorders complicating pregnancy (21\%) [17]. In the present study, premature rupture of membranes was the most common cause of referral $(15 \%)$. This is followed by pre-eclampsia and related conditions (14\%), and meconium stained liquor (11\%).

Previous caesarean sections were the cause of referral in $5 \%$ of cases in the present study which is similar to the study conducted by Goswami P et al(6\%) [10], Khatoon A et al (15\%)[16] and Gupta PR et al(7.62\%)[13]. The patients with previous caesarean section are referred to higher centres from $\mathrm{PHC} / \mathrm{CHC}$ due the unavailability of operation theatre, gynaecologist, anaesthesiologists, trained staff or basic infrastructure deficit [10].

In the present study, $7.4 \%$ of cases were referred due to non availability of blood and doctors; this can be compared to the study conducted by Goswami $\mathrm{P}$ et al where $16.87 \%$ of the cases were referred for the same reason. Government should take measures to improve health infrastructure facilities, make provisions for developing new blood banks and appoint trained gynaecologists in the peripheries to reduce the burden on tertiary centres [10].

$13.3 \%$ of the total referred cases were managed conservatively and discharged. This rate is similar to the study conducted by Gupta PR et al (7.76\%) [13], 


\section{Original Research Article}

Poornima $\mathrm{M}$ et al (11\%)[1], Goswami $\mathrm{P}$ et al (24\%) [10]. Here arises the concept of day care management of referral cases at tertiary care institute which might be helpful in reduction of burden of tertiary care institute [13].

Khatoon $\mathrm{A}$ et al had in their study reported $87 \%$ live births, $13 \%$ still births, $26.5 \%$ preterm births [16]. Rathi Charu et al in her study found that $90 \%$ were live births and 9\% were still births [17]. Poornima $\mathrm{M}$ et al in her study reported $91 \%$ live births and $9 \%$ still births [1]. In the present study, $99.05 \%$ were live births.

In the present study $4 \%$ had birth asphyxia and $23 \%$ had NICU admissions, which is comparable to the study conducted by Poornima $M$ et al where $27 \%$ of the babies needed NICU admissions [1].

In the present study $40 \%$ of the NICU admissions were for preterm care, $24 \%$ for meconium aspiration syndrome, followed by $12 \%$ for neonatal jaundice. These results are similar to the findings found in the study conducted by Poornima $\mathrm{M}$ et al where $47 \%$ of NICU admissions were for preterm care, $28 \%$ for respiratory distress [1]. The high rate of NICU admission is due to preterm delivery.

The neonatal death rate is $4 \%$ which is similar to the neonatal death rate in study conducted by Poornima $M$ et al (8\%) [1], Sabale U et al (10.23\%) [2], Gupta PR et al $(4.43 \%)$ [13]. In contrast to this, the study conducted by Rathi Charuet al had a neonatal mortality rate of $28.23 \%[17]$.

\section{Conclusion}

Childbirth is a normal physiologic process, but emergencies can arise anytime. The present study has shown that improper antenatal and intranatal care at the periphery level is responsible for poor maternal and perinatal outcome.

Hypertensive disorders of pregnancy have been one of the commonest causes of referral among high risk obstetric patients which can be better dealt at the tertiary care centre. Health care workers should be provided with the checklist; also administration of a dose of magnesium sulphate must be done in all cases of eclampsia and severe pre-eclampsia prior to referral.

The quality of information provided on the referral slips leaves a lot to be desired. Many of the slips had no vital data like blood pressure, pulse rate, temperature, and presence of foetal heart sounds. Also information regarding treatment given before referral of the case was missing in most of the referral slips. The cause of referral was unknown in 3\% of cases. This call for a more stringent documentation in referral slips and more coordination between the referral units and the higher centres are required. This study also recommends the development of a standard referral protocol, proper training in this regard and universal adherence to this in practice. Health education and awareness by mass media and non-government organisations can improve the health and social status of women in rural areas.

\section{Authors' contributions}

Dr. Mahendra G., Dr. Kavya B. S. and Dr. Ravindra S. Pukale carried out the study. Dr. Kavya B. S. developed the theory and performed the computations. Dr. M ahendra G. verified the analytical methods. Dr. Kavya B. S. to investigate more on reasons for referrals. All authors discussed the results and contributed to the final manuscript.

Funding: Nil, Conflict of interest: Nil

Permission from IRB: Yes

\section{References}

1. Poornima M, Rekha G Daver. Maternal and Fetal Outcome in Obstetric Referred Cases. Glob J Res Analys. 2018;7(2):544-7.

2. Sabale U, Patankar AM. A Study of Maternal and Perinatal Outcome in Referred Obstetrics Cases. JEvol Med Dent Sci.2015;4(26): 4448-4455.DOI: 10.14260/ jemds / 2015/643

3. Gupta PR, Chaudhari SN, Gonnade NV.Maternal and fetal outcome in referred patients to tertiary care centre, Sch J App Med Sci. 2016;4(5C):1624-31

4. Park K Textbook of Social and Preventive Medicine 17th ed. Jabalpur. BanarasidasBhanot Publishers 2000:632

5. Koblinsky M, Chowdhury ME, Moran A, Ronsmans C.Maternal morbidity and disability and their consequences: neglected agenda in maternal health. J Health Popul Nutr. 2012;30 (2): 124-30. DOI:10.3329/ jhpn. v30i2.11294

6. Lee AC, Lawn JE, Cousens S, Kumar V, Osrin D, Bhutta ZA. Linking families and facilities for care at birth: what works to avert intrapartum-related deaths? Int J Gynaecol Obstet. 2009;107(1):S65-85. DOI: 10. 1016/j. ijgo.2009.07.012. 


\section{Original Research Article}

7. World Health Organisation. Monitoringthe Building Blocksof Health Systems: A Handbook of Indicatorsand their Measurement Strategies. Geneva:WHO;2010

8. Travis P, Bennett S, Haines A, Pang T, Bhutta Z, Hyder AA. Overcoming health-systems constraints to achieve the Millennium Development Goals. Lancet. 2004; 364 (9437):900-6. DOI:10.1016/S0140-6736(04) $16987-0$

9. Paxton A, Bailey P, Lobis S. The United Nations Process Indicators for emergency obstetric care: Reflections based on a decade of experience. Int J Gynaecol Obstet. 2006;95(2):192-208. DOI:10.1016/j. ijgo. 2006. 08.009

10. Goswami P, Bindal J, Chug N. To study pattern of obstetric cases referred at tertiary care centre in Central India. Int J ReproductContracep, Obstet Gynecol. 2017; 6(6): 2370-2374.DOI: http://dx.doi.org/10.18203/23201770.ijrcog20172315

11. Sumera S, Nuzhat R, Sadia A. Fetomaternaloutcome in cases referred to tertiary care hospital after trial of labour. JSZMC. 4(2):444-447.
12. Morsheda B, Shamsun N, Hashima EN; Assessing the MANOSHI Referral System Addressing Delays in Seeking Emergency Obstetric Care in Dhaka's Slums. MANOSHI working paper series no.10.2010; ManoshiWP 10:1-36 published by ICDDR,B,BRAC

13. Gupta PR, Chaudhary SN, Gonnade NV. Maternal and fetal outcome in referred patients to tertiary care centre Sch J App Med Sci.2016;4(5C):1624-63.

14. Devineni K, Sodumu N. A study of spectrum of referral pattern at a tertiary teaching hospital towards better obstetric care. IAIM, 2016;3(8):193-198.

15. Patel HC, Singh BB, Moitra M, Kantharia SL. Obstetric Referrals: scenario at a primary health centre in Gujarat. Natl J Community Med. 2012;3(4):711-4.

16. Khatoon A, Hasny SF, Irshad S, Ansari J , An audit of obstetric referrals to Abbasi Shaheed Hospital. Pak J Surg. 2011;27(4):304-8.

17. Charu R, Kamal G, Neelu S. Review of referred obstetric cases-Maternal and Perinatal Outcome. Bombay Hospital J. 2010; 52(1):53.

\section{How to cite this article?}

Mahendra G, Kavya B. S, Pukale R. S. Study of maternal and perinatal outcome in referred obstetric cases. Obs Rev: $J$ obstet Gynecol 2019;5(2):106-111.doi:10.17511/joog.2019.i02.04. 